\title{
Flapless implant surgery on atrophied alveolar ridge in a patient with growth disorder
}

\author{
Du-Hyeong Lee* \\ Department of Prosthodontics, School of Dentistry, Kyungpook National University, Daegu, Republic of Korea
}

The growth disorder influences craniofacial development and early loss of permanent teeth. This case reports the importance of computerized tomography (CT) and surgical guide to identify horizontal bone loss, adjacent teeth and to guide drills when placing implants in a short stature patient. The patient has idiopathic short stature and the 3rd grade of intellectual disability. To recover posterior mandibular teeth, implant treatment was planned. CT images showed that the adjacent teeth were located markedly to the buccal side. A CT-based surgical guide was fabricated and implants was placed using flapless surgery. Bone dehiscence and fenestration may happen when the surgical guide was fabricated just based on adjacent clinical crowns. Thus, it is essential to analysis bone and teeth and to make surgical guide through CT, especially in atrophied bone on grow disorder patients. Furthermore, systematic researches are recommended to elucidate the relationship between growth disorder and tooth malposition. (J Dent Rehabil Appl Sci 2014;30(2):170-5)

Key words: growth discorder; alveolar bone atropy; computerized tomography; flapless surgery; implant guide; tooth malposion

\section{서론}

성장장애는 진단학적으로 일차성 성장장애, 이차성 성 장장애 그리고 원인을 알 수 없는 그룹으로 나눌 수 있 다. ${ }^{1}$ 이 세 번째 그룹은 최근에 특발성 저신장으로 알려 져 있다. 일차성 성장장애는 임신 중에 골격 이형성증과 염색체 이상이 나타나거나 다른 유전적인 요인으로 저신 장이 온 것이고, 이차성 성장장애는 영양실조, 스트레스, 만성전신 질환으로 인해 발생한다. 마지막의 특발성 저 신장은 환자의 성, 연령, 인구에 해당하는 평균키에서 2 배의 표준편차보다 작은 키를 가지면서 그 원인을 파악 하지 못하는 경우를 나타낸다. ${ }^{2}$

성장장애 환자에 대한 두개안면부의 성장 방식에 대한

${ }^{*}$ Correspondence to: Du-Hyeong Lee, DDS, MS

Department of Prosthodontics, College of Dentistry, Kyungpook National University, 2175 Dalgubeol dae-ro, Jung-gu, Daegu, 700-412, Republic of Korea Tel: +82-53-600-7676, Fax: +82-53-427-0778, E-mail: deweylee@knu.ac.kr Received: February 24, 2014/Last Revision: April 19, 2014/Accepted: April 24, 2014
연구에 대해서는 지속적 관심이 있어 왔다., ${ }^{3,4}$ 그리고 염 색체 또는 성장 호르몬의 이상이 없고, 작은 머리 둘레를 가지며, 경계선 정신지체를 나타내는 성장장애 환자에서 왜소치, 부분 무치악, 구근상 치근(bulbous roots), 유치 의 만기잔존, 장수치, 치근 외흡수와 같은 구강 상태를 보 이는 증례가 발표된 바 있다., ${ }^{5,6}$

무피판 임플란트 수술은 절개와 봉합 과정이 없어서 위와 같은 합병증을 최소화 할 수 있으며, 술 후 회복이 빠르고 비교적 수술 시간이 짧기 때문에 환자의 만족도 와 편안함이 증가한다. ${ }^{7}$ 그러나 피판을 거상하지 않는 경 우 치조골의 상태를 눈으로 직접 확인할 수 없으므로 골 삭제의 각도가 잘못되면 치조골의 천공, 열개 가능성이 있다. ${ }^{8}$

Copyright(C 2014 The Korean Academy of Stomatognathic Function and Occlusion. (c) It is identical to Creative Commons Non-Commercial License. 
무피판 수술의 문제점을 최소화 하기 위해 여러 가지 방법들이 사용되고 있다. ${ }^{9}$ 단일 치아의 회복일 경우 치 근단 방사선 사진과 진단모형의 이용 그리고 임상적 진 단을 통해 치조골의 너비를 충분히 알아낼 수 있다. ${ }^{10,11}$ 부가적으로 무치악 부위의 치조골 상태와 주변의 점 막 두께를 확인하기 위해 치은 관통 탐침(transgingival probing, bone sounding)으로 비교적 정확하게 골과 연조직의 두께를 확인할 수 있다. ${ }^{11,12}$ 컴퓨터 단층촬영 (computerized tomography: CT)은 수술부위의 상태를 확인하고 주의해야 할 주변 해부학적 구조를 확인하는 데 탁월한 정확도와 단면영상을 제공하므로 구치부나 복잡한 임플란트 식립시에 진단 및 계획 도구로 사용되 고 있다. ${ }^{913}$ 임플란트 스텐트는 모형 혹은 CT를 기반으 로 제작되며 제작된 방식에 따라 임플란트 식립시 위치 혹은 방향을 안내한다. ${ }^{14}$ 이러한 스텐트는 무피판 방식 으로 임플란트 식립시 식립 정확성과 술자 편의성을 증 대시킨다.

지금까지 성장장애 환자에 대한 두개안면의 성장 패 턴에 대한 연구는 진행되어 왔지만, ${ }^{3,4}$ 성장장애 환자에 서 치아의 치조골에 대한 위치 이상과 임플란트 식립에 대한 증례는 거의 보고 되지 않았다. 본 증례의 목적은 성장장애 환자에서 치아를 조기 상실한 부위에 무피판 술식으로 임플란트를 식립 시 CT를 이용한 인접치아의 위치 평가의 중요성과 임플란트 가이드의 필요성을 확 인하는 것이다.

\section{증례 보고}

20세의 여환이 저작 기능의 회복을 주소로 경북대학 교 치과보철과에 내원하였다. 환자는 2013년에 경북대 학교 소아청소년과에서 염색체 수의 이상이 없는 특발 성 저신장으로 진단받았으며, 2008년에 부산대학교병 원 정신건강의학과에서 정신지체 3 급을 진단받았다. 신 장은 $138 \mathrm{~cm}$, 체중은 $57 \mathrm{~kg}$ 으로 10세 정도의 발육상태 를 보였다. 2007년에 부산대학교 치과병원 소아치과에 서 우식으로 35,36 번 치아를 발거한 치과병력이 있었 다. 운동 신경 발달, 혈액검사, 흉부방사선 검사는 정상 정상범주를 보였다.

구강의 임상 및 방사선 검사를 시행한 결과 악골은 골 격성 3급 부정교합 양상이었고, 전치부는 반대교합을 나타내었다(Fig. 1). 상하악의 악궁 모양은 둥근 형태이 고, 전치부 치간이개가 있었다(Fig. 2, 3). 54, 74, 84번 유

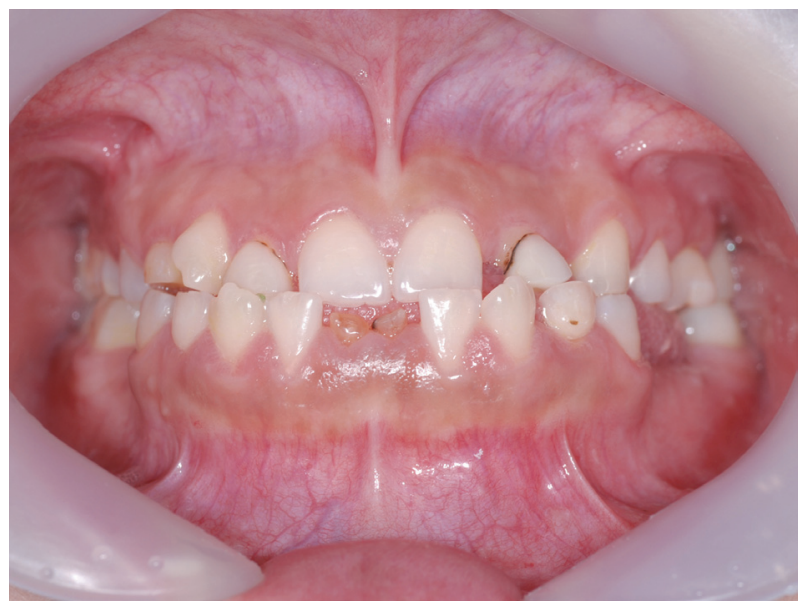

Fig. 1. Initial clinical photograph; frontal view.

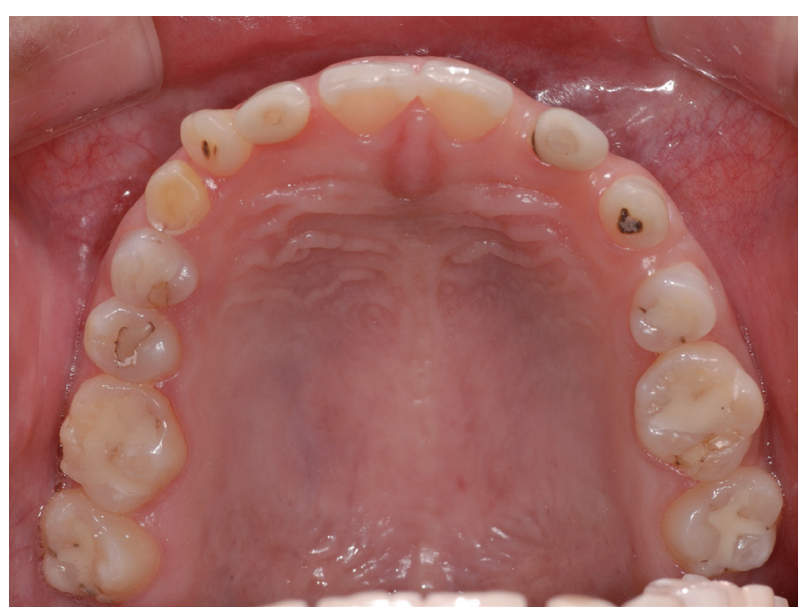

Fig. 2. Initial clinical photograph; upper view.

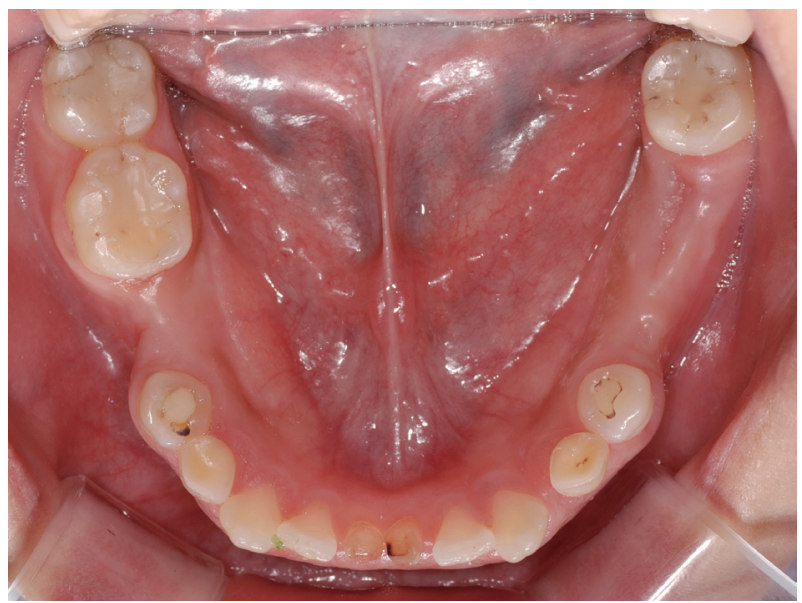

Fig. 3. Initial clinical photograph; lower view. 
구치가 만기잔존하고 있었으며, $24,35,36,45$ 번 치아는 상실된 상태였다(Fig. 4). 전체 치아의 치근이 짧은 편이 였고, 37,47 번 치아는 장수치였다. 31,41 번 치아는 부 분 치관 파절(Ellis 2급) 양상을 보였다. 치아가 상실된 구치부에서 수평적 치조골 흡수(Siebert 1급) 양상을 보 였는 데, 특히 34번과 44번에 인접한 후방 부위에서 심 한 협측 골흡수를 나타내었다. 구강 위생은 양호했고, 연조직은 건강하였다.

하악의 상실된 치아 부위에 임플란트를 이용한 고정 성 보철을 계획하였다. 환자의 법정대리인과 상의 시 비 침습적인 치료를 원하여 판막을 거상하지 않고 임플란 트를 식립하기로 하였다. 수평적 치조골 흡수 양상의 확 인과 임플란트 가이드 제작을 위해 컴퓨터 단층촬영을 시행하였다. 특징적으로 무치악 부위에 인접한 34번 치 아의 횡단면 영상에서 치아가 하악골에 기준해서 협측 으로 위치되고 기울어서 있는 것이 관찰되었다(Fig. 5). 임플란트 가이드는 인접치의 위치와 기울어짐을 반영하 여 제작하였다.

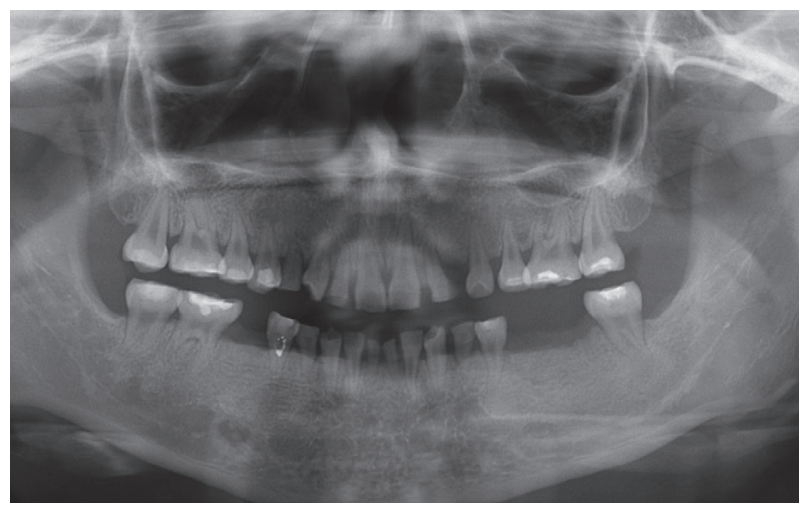

Fig. 4. Initial panoramic view.
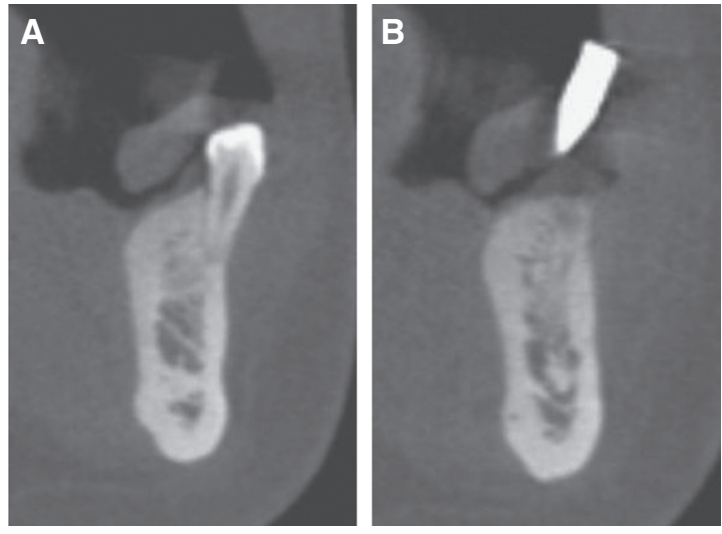

Fig. 5. Initial cross-sectional CT image (A) \#34 area, (B) edentulous area with radiographic stent.
국소마취 하에 치조정상에 작은 수평 절개를 한 후 미리 제작된 임플란트 가이드를 이용하여 판막의 거 상 없이 임플란트를 식립하였다(Fig. 6). 임플란트는 길 이 $10 \mathrm{~mm}$, 너비 $4.0 \mathrm{~mm}$ 의 SuperLine (Dentium, Seoul, Korea)을 사용하였다(Fig. 7, 8). 수술 후에 치유지대주 를 바로 연결하여 지대주의 상단부가 구강 내로 노출되 도록 하였다.
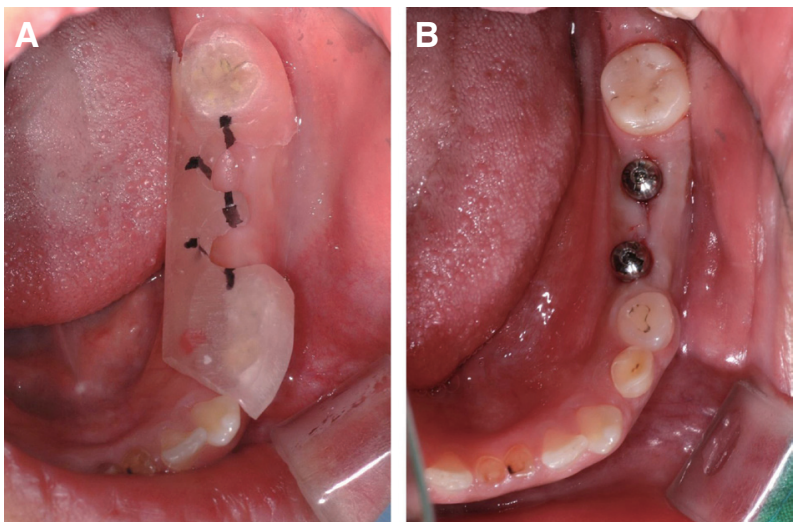

Fig. 6. (A) Before surgery with implant guide, (B) After surgery.

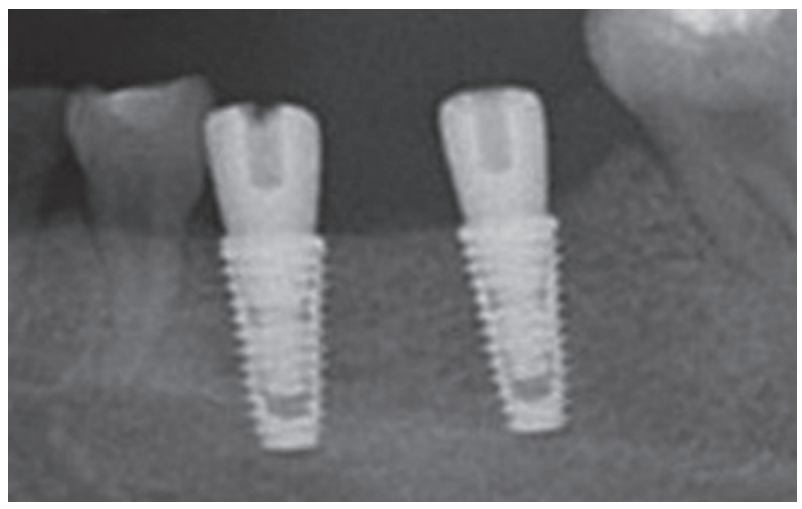

Fig. 7. Periapical view after surgery.

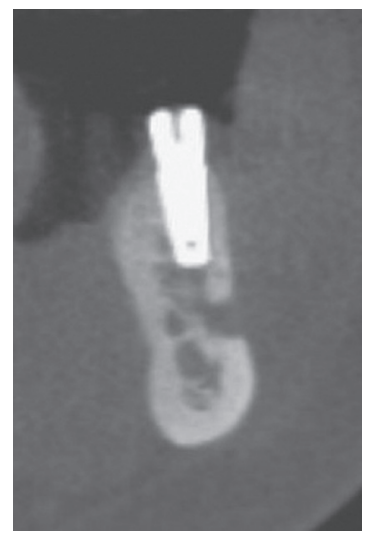

Fig. 8. Cross sectional CT image after surgery. 


\section{고찰}

본 증례의 환자는 원인이 명확하지 않은 성장장애를 가진 경우로 $24,35,36,45$ 번 치아가 상실되어 있었다. 일반적으로 구강 위생 관리가 잘 되지 않았을 때 우식 또는 치주질환으로 치아를 조기 상실한다. 치관 및 치근 우식은 구치에서 가장 빈번히 발행하고, ${ }^{15}$ 구치부의 우 식 감수성이 높은 것은 구치부가 전치부보다 먼저 상실 되는 것과 연관 된다. ${ }^{16}$ 본 증례와 같이 치근이 짧고 장수 치를 가지는 경우 우식 혹은 치주 질환 시 치아를 조기 상실할 가능성이 높아진다. 그리고 3급 정신지체가 동 반하고 있었는 데 구강위생 관리 능력이 상대적으로 저 하됨에 따라 우식 이환율이 더욱 높아져 치아 상실을 발 생시킨 것으로 생각된다.

치아가 상실된 경우 1 년 안에 골의 약 $25 \%$ 가량이 소 실되며, 3 년 동안 $40-60 \%$ 정도가 소실된다. ${ }^{17,18}$ 치조 골의 위축은 협측 치조골의 상실(79\%)이 설측의 상실 (21\%)보다 크다. ${ }^{19}$ 이러한 흡수 양상은 치조제를 얇게 만들고 치조골의 각도를 변화시켜 임플란트 식립시 각 도를 제한하고 임플란트의 순측을 따라 적절한 골조직 의 두께를 얻는데 어려움을 주게 된다. ${ }^{20}$ 본 증례에서도 임상 및 방사선 촬영 시 치아를 조기 상실한 부위에 협 측의 치조골 흡수가 심한 것을 관찰할 수 있었다.

흥미로운 것은 본 증례의 환자의 CT 단면 영상에서 무치악 부위의 인접치가 치조골 상에서 비정상적으로 협측에 위치하고 있었다는 것이다. 일반적으로 자연치 사이의 무치악 공간에 임플란트를 식립하는 경우 인접 치의 위치를 고려해서 식립 위치를 결정한다. 본 증례와 같이 인접치아가 협측으로 위치된 경우 CT를 기반으로 않고 인접치를 기준으로 스텐트를 제작하고 식립하는 경우에는 협측 골의 열개 혹은 천공이 발생할 가능성이 높다.

성장장애와 치아가 협측으로 위치된 것과의 연관성은 본 증례만으로 단정 지을 수 없다. 하지만 성장장애가 치아의 형태에 영향을 미쳐 크기와 형태에 영향을 미치 는 것과 같이 악골내에서 치아의 위치에도 영향을 미칠 수도 있다. 따라서 성장장애와 악골내 치아위치와의 관 련성을 파악하기 위해 더욱 많은 증례에서 체계적인 분 석이 필요할 것이다.

\section{결론}

성장장애를 가진 환자에서 선천적 치아 형태이상과 구강위생 관리 불량으로 인한 치아의 조기 상실과 치아 의 위치 이상이 발생할 가능성이 있다. 그러므로 위축된 골에 임플란트를 식립시 CT의 단면 영상에 기반한 골 흡수와 인접치의 평가, 그리고 임플란트 가이드의 제작 이 요구된다.

\section{References}

1. Wit JM, Clayton PE, Rogol AD, Savage MO, Saenger PH, Cohen P. Idiopathic short stature: definition, epidemiology, and diagnostic evaluation. Growth Horm IGF Res 2008;18:89-110.

2. Pedicelli S, Peschiaroli E, Violi E, Cianfarani S. Controversies in the definition and treatment of idiopathic short stature (ISS). J Clin Res Pediatr Endocrinol 2009;1:105-15.

3. van Erum R, Mulier M, Carels C, de Zegher F. Short stature of prenatal origin: craniofacial growth and dental maturation. Eur J Orthod 1998;20:41725.

4. Kjellberg H, Beiring M, Albertsson Wikland K. Craniofacial morphology, dental occlusion, tooth eruption, and dental maturity in boys of short stature with or without growth hormone deficiency. Eur J Oral Sci 2000;108:359-67.

5. Bazopoulou-Kyrkanidou E, Dacou-Voutetakis C, Nassi H, Tosios K, Kyrkanides S, Damoli M. Microdontia, hypodontia, short bulbous roots and root canals with strabismus, short stature, and borderline mentality. Oral Surg Oral Med Oral Pathol 1992;74:93-5.

6. Gardner DG, Girgis SS. Taurodontism, short roots, and external resorption, associated with short stature and a small head. Oral Surg Oral Med Oral Pathol 1977;44:271-3.

7. Oh TJ, Shotwell J, Billy E, Byun HY, Wang HL. Flapless implant surgery in the esthetic region: advantages and precautions. Int J Periodontics Restorative Dent 2007;27:27-33.

8. Campelo LD, Camara JR. Flapless implant surgery: A 10-year clinical retrospective analysis. Int J Oral 
Maxillofac Implants 2002;17:271-6.

9. Ozan O, Turkyilmaz I, Yilmaz B. A preliminary report of patients treated with early loaded implants using computerized tomography-guided surgical stents: flapless versus conventional flapped surgery. J Oral Rehabil 2007;34:835-40.

10. Wyatt CC, Pharoah MJ. Imaging techniques and image interpretation for dental implant treatment. Int J Prosthodont 1998;11:442-52.

11. Stumpel LJ 3rd. Cast-based guided implant placement: a novel technique. J Prosthet Dent 2008;100: 61-9.

12. Nanda A, Jain V. Simplistic partially limiting surgical guide for flapless implant placement: a case report. J Oral Implantol 2012;38:639-41.

13. Iplikçioğlu H, Akça K, Cehreli MC. The use of computerized tomography for diagnosis and treatment planning in implant dentistry. J Oral Implantol 2002;28:29-36.

14. Katsoulis J, Pazera P, Mericske-Stern R. Prosthetically driven, computer-guided implant planning for the edentulous maxilla: a model study. Clin Implant
Dent Relat Res 2009;11:238-45.

15. Katz RV, Neely AL, Morse DE. The epidemiology of oral diseases in older adults. Copenhagen; Munksgaard; 1996. p. 263-301.

16. Carr AB, McGivney GP, Brown DT, McCracken WL. McCracken's removable partial prosthodontics. $12^{\text {th }}$ ed. St. Louis; Mosby; 2010. p. 1-18.

17. Carlsson GE, Thilander H, Hedegård B. Changes in contour of the maxillary alveolar process after extractions with or without insertion of an under immediate full denture. Acta Odontol Scand 1967;25:21-43.

18. Pietrokovski J, Massler M. Alveolar ridge resorption following tooth extraction. J Prosthet Dent 1967; $17: 21-7$.

19. Ostler MS, Kokich VG. Alveolar ridge changes in patients congenitally missing mandibular second premolars. J Prosthet Dent 1994;71:144-9.

20. Rosenstiel SF, Land MF, Fujimoto J. Contemporary fixed prosthodontics. $4^{\text {th }}$ ed. St. Louis; Mosby; 2006. p. $379-88$. 


\section{성장 장애를 가진 부분 무치악 환자에서 위축된 골에 무피판 임플란트 수술 증례}

\section{이두형*}

경북대학교 치과대학 치과보철학교실

성장장애는 두개안면부의 골격성장과 영구치의 조기상실에 영향을 미친다. 본 증례는 성장장애 환자에서 치아를 조기 상실한 부위에 무피판 술식으로 임플란트를 식립 시 컴퓨터 단층촬영(CT)을 통한 인접치아의 확인과 임플란트 가이드 의 필요성을 살펴보았다. 특발성 저신장과 3급 정신지체의 20 세의 여환에서 구치의 회복을 위해 임플란트 고정성 보철 을 계획하였다. CT 영상에서 인접치가 심하게 협측으로 위치되어 있었고, 이를 반영하여 가이드를 제작후 임플란트를 식립하였다. 이상 위치된 인접치를 기준으로 임플란트를 식립할 경우 협측 골의 천공이 발생할 수 있다. 그러므로 성장 장애 환자에서 치아 조기 상실부에 임플란트를 식립 시 CT를 통한 치아의 위치 확인과 가이드의 제작이 요구된다.

(구강회복응용과학지 2014;30(2):170-5)

주요어: 성장장애; 치조골 위축; 컴퓨터 단층촬영; 무피판 수술; 임플란트 가이드; 치아 위치이상 